\title{
Disfunctions in the anthocyanin accumulation of Vitis vinifera L. varieties studied by a targeted resequencing approach
}

\author{
Gabriella De Lorenzis, ${ }^{\mathrm{a}, 1, *}$, Laura Rustioni ${ }^{\mathrm{b}, 1}$, Carlo Pozzi ${ }^{\mathrm{a}}$ and Osvaldo Failla ${ }^{\mathrm{a}}$ \\ ${ }^{a}$ Department of Agricultural and Environmental Sciences, Via Celoria, Milano, Italy \\ ${ }^{\mathrm{b}}$ Department of Biological and Environmental Sciences and Technologies, University of Salento, Lecce, Italy
}

Received 4 September 2019; accepted 20 February 2020

\begin{abstract}
.
BACKGROUND: The pathway of anthocyanin biosynthesis, and its alterations leading to berry colour modification, are well known in grape skin. This variability could affect both quantity and quality of pigment accumulation.

OBJECTIVE: The present work is focused on 15 grapevine cultivars selected to represent a high variability in the phenotypical colour traits in order to highlight new polymorphisms related to the flavonoid pathway.

METHODS: Twenty-one genes involved in the biosynthetic pathway of anthocyanins were studied via targeted resequencing and were correlated with phenotypic data (anthocyanin profiles and spectroscopy indices).

RESULTS: Single nucleotide polymorphism (SNP) and InDel (insertion/deletion) polymorphisms were detected. Out of 1751 polymorphic loci, 68\% were SNPs and 32\% were InDels (568). Cluster analysis and SPLS-DA were used to investigate the genetic relationships among the cultivars, confirming the large range of phenotypical variability. Statistically significant correlations were detected between accumulation of cyanidin-based anthocyanins and genetic polymorphisms in two structural genes and one transcription factor putatively involved in the anthocyanin biosynthetic pathway.

CONCLUSIONS: The understanding of the polymorphisms related to the anthocyanin accumulation could support future selection of new pink table grape varieties with increased appeal on the consumers.
\end{abstract}

Keywords: Colour, flavonoid, grape, InDel, pink berry, polymorphisms, SNP

\section{Introduction}

In grapevine (Vitis vinifera L.), the berry colour is determined in the berry skin by anthocyanins, which are red, purple, violet and blue pigments synthetized in many flowers and fruits. Grapevine berries synthesize

\footnotetext{
${ }^{1}$ Both authors made equal contribution.

*Corresponding author: Gabriella De Lorenzis, Department of Agricultural and Environmental Sciences, Via Celoria, 2 - 20133 Milano, Italy. Tel.: +39 0250316565; Fax: +39 0250316553; E-mail: gabriella.delorenzis@unimi.it.
} 
five anthocyanidins (cyanidin, peonidin, delphinidin, petunidin and malvidin) and their content and patterns of accumulation are cultivar-specific, leading to a distinctive flavonoid profile [1,2]. Cyanidin and peonidin are responsible for the reddish hues of the berries, while delphinidin, petunidin and malvidin give rise to hues from blue to purple. The varieties accumulating mainly cyanidin-3-O-glucoside show a salmon pink colour [3].

Anthocyanins are synthesized in grapes following a multi-branched phenylpropanoid pathway [4,5]. The early steps of the pathway include the transformation of phenylalanine to cinnamate by the phenylalanine-ammonialyase (PAL), which is then converted to $p$-coumarate by cinnamate-4-hydroxylase $(\mathrm{C} 4 \mathrm{H})$. The $p$-coumarate is converted in coumaroyl-CoA through the action of 4-coumarate-CoA-ligase (4CL). This compound is converted into chalcone $\left(2,4,6,4^{\prime}\right.$-tetrahydroxychalcone) by chalcone synthase (CHS). Chalcone isomerase (CHI) and flavonoid-3-hydroxylase (F3H) lead to dihydrokaempferol. The flavonoid-3'-hydroxylase (F3' $\mathrm{H})$ and the flavonoid-3' 5'-hydroxylase (F3'5'H) use dihydrokaempferol to produce dihydroquercitin and dihydromyricetin, respectively. The latter two molecules act as precursors for disubstituted (cyanidin-based), or trisubstituted (delphinidin-based) anthocyanins, respectively. Leucocyanidin and leucodelphinidin are derived from dihydroquercitin and dihydromyricetin, respectively. The subsequent action of leucoanthocyanidin dioxygenase (LDOX) leads to the production of anthocyanidins, that are eventually glycosylated by UFGT (UDP-glucose:flavonoid 3-O-glucosyltransferase). Cyanidin-3-O-glucoside and the delphinidin-3-O-glucoside are the first two stable anthocyanins to be synthesized [6]. Anthocyanin $O$-methyltransferase (AOMT) eventually methoxylates cyanidin-3-O-glucoside to peonidin-3-O-glucoside and delphinidin-3-O-glucoside to petunidin-3-O-glucoside and malvidin-3-O-glucoside [7].

In plants, the synthesis of anthocyanins is controlled by transcription factors of the MYB, basic helix-loophelix (bHLH or MYC), and WDR (or WD40) classes [8, 9]. In grapevine, VvMybA1 and VvMybA2 induce the transcription of VvUFGT $[10,11]$. Both transcription factors are located on chromosome 2 and their effect is additive [12]. The key roles of VvMybA1 and VvMybA2 in the accumulation of anthocyanins has been also demonstrated in skin colour mutants [3, 14-18]. In white cultivars, the loss of pigmentation is due to the retrotransposon-driven inactivation of VvMybA1 [13] and to two non-conservative mutations driving the VvMybA2 inactivation [11].

Nevertheless, in order to fully explain the high phenotypic variability of pigmented grapevine cultivars, in terms of both quantitative (red/pink) and qualitative accumulation of anthocyanins, it may be necessary to include metabolic disfunctions other than those caused by mutations in the transcription factors. The aim of this work was to discover new genetic determinants of anthocyanin biosynthesis. Towards this goal, 15 grapevine cultivars showing high variability for the accumulation of anthocyanins (five showing a predominance of cyanidin-3-Oglucoside, five of peonidin-3- $O$-glucoside and five of malvidin-3- $O$-glucoside [3, 19]) were selected. Twenty-one genes of the anthocyanin pathway were re-sequenced using next-generation sequencing (NGS) technology and their genetic polymorphisms were recorded for each cultivar. The genetic polymorphisms were correlated with the phenotypic data related to anthocyanin accumulation (HPLC and spectroscopy) collected during different years and experimental plans in the seasons 2011, 2012, 2013, 2014 [3, 19] and 2015.

\section{Material and methods}

\subsection{Plant material}

Fifteen $V$. vinifera varieties representing the phenotypic variability (in terms of colour intensity) of pigmented berried cultivars were analysed in this study (Table 1). These varieties were selected based on their anthocyanin quantity and quality $[3,19]$. Five genotypes show a high accumulation of cyanidin-3-O-glucoside, five accumulate mainly malvidin-3-O-glucoside and five peonidin-3-O-glucoside. To our knowledge, no grape genotypes have been found with delphinidin- or petunidin-3-O-glucoside as the dominant pigments. 
Table 1

List of grape varieties ( $V$. vinifera) analyzed, arranged based on predominant anthocyanin in their anthocyanin berry profiles [3], and passport data (berry skin colour, origin and utilization), as reported in the Vitis International Variety Catalogue (http://www.vivc.de/)

\begin{tabular}{lcllll}
\hline Variety & ID sample & Predominant anthocyanin & Berry skin color & Origin & Utilization \\
\hline Fernand Rose & 2 & Cyanidin-3- $O$-glucoside & Rose & France & Table grape \\
Chasselas Noir & 6 & & Rouge & France & Wine and table grape \\
Comtessa & 10 & & Rose & Germany & Wine grape \\
Faberrebe & 12 & & Rose & Germany & Wine grape \\
Rkatsiteli Vardisperi & 15 & & Rose & Georgia & Wine and table grape \\
Cabernet Sauvignon & 1 & Malvidin-3- $O$-glucoside & Noir & France & Wine grape \\
Cannonau & 4 & & Noir & Spain & Wine grape \\
Muscat Rouge de Madere & 11 & & Rouge & Italy & Wine and table grape \\
Primitivo/Zinfandel & 13 & & Noir & Balkan & Wine grape \\
Ghrubela Kartlis & 14 & & Gris & Georgia & Wine grape \\
Coada Vulpii & 3 & Peonidin-3- $O$-glucoside & Rose & Romania & Table grape \\
Angulato & 5 & & Noir & Greece & Table grape \\
Grignolino & 7 & Noir & Italy & Wine grape \\
Veltliner Fruehrot & 8 & Rose & Italy & Wine and table grape \\
Cardinal & 9 & & Rouge & USA & Wine and table grape \\
\hline
\end{tabular}

All the plants were grown in the germplasm collection of the Dipartimento di Scienze Agrarie ed Ambientali (University of Milan) located in Torrazza Coste (Pavia, Italy), already described in Rustioni et al. [19]. The vineyard coordinates are longitude $9^{\circ} 05^{\prime}$, latitude $44^{\circ} 58^{\prime}$, elevation $144 \mathrm{~m}$ a.s.l.. The experimental site has a mesothermal climate with transitional characteristics between Oceanic $(\mathrm{Cfb})$ and Mediterranean (Csa) types, according to Koeppen's classification [20]. The temperatures are 11.7; 0.7 and $22.4^{\circ} \mathrm{C}$ as annual; January and July averages respectively. The annual rainfall varies between 600 and $800 \mathrm{~mm}$ with two maxima (in spring and autumn). The hilly field terrace has a slight eastern exposure. The soil is a typical clay soil (Udic Paleustalfs fine silty, mixed, superactive, mesic, following the USDA soil taxonomy [21]). The plant density is about 4000 vines/ha ( $2.5 \mathrm{~m}$ interrow and $1 \mathrm{~m}$ intrarow). Vines are trained to the Guyot system: winter pruning leave a cane of 10-12 buds and a two-bud spur. The interrow soil is covered by native grasses and chemical fertilizers are not generally used.

\subsection{Berries phenotypic description}

Ripe berries (phenological stage 89 of the BBCH scale, following Meier [22], identified by visual inspection and grape tasting), were collected during the 2011, 2012, 2013, 2014 and 2015 seasons and analysed for carpological descriptors (berry surface, berry weight, skin weight and volume) and anthocyanin characterization (HPLC and spectroscopy).

According to the protocol reported in Rustioni et al. [19], a carpological evaluation of varieties was obtained by weighting berries and skins and by measuring the diameters to calculate surface and volume. Berries were compared to prolate or oblate spheroids $(\mathrm{a}=\mathrm{b}>\mathrm{c}$ in oblate ellipsoid of revolution and $\mathrm{a}=\mathrm{b}<\mathrm{c}$ in prolate ellipsoid of revolution, where a, b and c are the semi-principal axes' lengths). The surfaces (S) and the volumes (V) were calculated as follow:

$$
V=\frac{3}{4 \pi} * a b c
$$




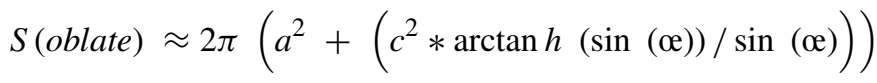

$$
\begin{aligned}
& S(\text { prolate }) \approx 2 \pi\left(c^{2}+a c * \propto / \sin (œ)\right) \\
& œ=\operatorname{arcos}(c / a)
\end{aligned}
$$

Anthocyanin profiling was performed according to Rustioni et al. [3] by HPLC analysis on three replicates of three berry skins from three representative bunch samples per each genotype. Anthocyanin profiles were determined at $520 \mathrm{~nm}$ by using a Shimadzu HPLC LC-10 AD (Shimadzu Co. Tokyo, Japan) connected to a Shimadzu UV-VIS detector SPD-10A. The anthocyanin profiles were outlined as the relative levels (\%) of delphinidin-3-O-glucoside, cyanidin-3-O-glucoside, petunidin-3-O-glucoside, peonidin-3-O-glucoside and malvidin-3-O-glucoside. Esterification was considered as acetyl and $p$-coumaroyl derivatives of the main anthocyanin of each cultivar. Derived parameters (e.g. disubstituted or methoxylated anthocyanins) were calculated. The percentage of methoxylation was obtained considering the ratio among methoxylated substitutions and - $\mathrm{OH}$ substituents available for methoxylation by the formula:

$$
\text { percentage of methoxylation }(\%)=\frac{(\text { pet } * 1+\text { peo } * 1+\text { mal } * 2) * 100}{\operatorname{del}^{*} 2+\text { cya } * 1+\text { pet } * 2+\text { peo } * 1+\text { mal } * 2}
$$

del $=$ relative concentration of delphinidin-3-O-glucoside

cya $=$ relative concentration of cyanidin-3-O-glucoside

pet $=$ relative concentration of petunidin-3-O-glucoside

peo $=$ relative concentration of peonidin-3-O-glucoside

mal $=$ relative concentration of malvidin-3-O-glucoside

Anthocyanin profiles recorded in 2014 year (already published in Rustioni et al. [3]) were elaborated together with profiles collected in the 2015 season.

Transmittance and reflectance spectroscopy data carried out on berries collected in 2011, 2012, 2013 and 2014 seasons have already been published in Rustioni et al. [3] and Rustioni et al. [19]. Total anthocyanins were quantified by using a JASCO 7800 spectrophotometer (JASCO, Mary's Court, Easton, Maryland). Analyses were carried out on extracts by reading the absorbance at $540 \mathrm{~nm}$ and by using a malvidin-3-O-glucoside calibration curve. Spectrophotometric indexes (colour index and group), were obtained using a Jaz System spectrometer (Ocean Optics, B.V.), completed with a DPU module and ILX511b detector equipped channel, OFLV-3 filter, L2 lens, 50 mslit as installed options, and a reflection probe QR600-7-VIS125. Colour group was identified by visual inspection of the reflectance spectra, while colour index was calculated using the formula reported in Rustioni et al. [19]:

$$
\text { Colour index }=\lambda f_{\max }^{\prime}(\lambda>680) / R \% 680
$$

$$
R=\text { reflectance; } \lambda=\text { wavelength } 680=\text { reference wavelength }(\mathrm{nm}) \text {. }
$$

\subsection{Targeted resequencing}

DNA extraction was performed starting from $0.1 \mathrm{~g}$ of young leaves. The extraction was carried out using the Qiagen DNeasy Plant Mini Kit (Qiagen-Hilden, Germany), following the manufacturer's instructions. The DNA integrity was evaluated via agarose gel electrophoresis, and the concentration was measured by Qubit ${ }^{\circ}$ DNA BR Assay Kit by a Qubit ${ }^{\circledR}$ 3.0 Fluorometer (Thermo Fisher, Life Technologies, Carlsbad, CA). The quality was checked by NanoDrop Spectrophotometer (Thermo Scientific), to evaluate the 260/230 and 260/280 
Table 2

List of genes related to anthocyanin biosynthetic pathway analyzed and their position on the grapevine reference genome

\begin{tabular}{lll}
\hline Gene ID & Gene name & Chromosome:Position \\
\hline F3'H & flavonoid 3' hydroxylase & chr17:8011074..8015002 \\
F3'5'H & flavonoid 3' '' hydroxylase & chr6:15714328..15716526 \\
F3H1 & flavanone 3-hydroxylase 1 & chr4:19929309..19931725 \\
F3H2 & flavanone 3-hydroxylase 2 & chr18:12302678..12305409 \\
DFR & dihydroflavonol reductase & chr18:10907281..10910349 \\
LDOX & leucoanthocyanidin dioxygenase & chr2:4281946..4284248 \\
UFGT & UDP-glucose:flavonoid 3-Oglucosyltransferase & chr16:2332844..2335021 \\
AOMT1 & anthocyanin $O$-methyltransferase 1 & chr1:20849798..20852873 \\
AOMT2 & anthocyanin $O$-methyltransferase 2 & chr1:20827871..20831096 \\
AOMT3 & anthocyanin $O$-methyltransferase 3 & chr1:20818167..20820393 \\
MYBPA1 & MYBPA1 transcription factor & chr15:17211363..17213445 \\
Myb5a & Myb5a transcription factor & chr8:20865079..20867014 \\
Myb5b & Myb5b transcription factor & chr6:744220..746206 \\
MybA1 & MybA1 transcription factor & chr2:14239408..14241214 \\
MybA2 & MybA2 transcription factor & chr2:14178966..14181124 \\
Myb4a & Myb4a transcription factor & chr3:1583662..1585690 \\
Myb4b & Myb4b transcription factor & chr4:20251594..20253327 \\
MYBC2-L2 & MYBC2-L2 transcription factor & chr17:2462809..2464519 \\
MYCA1 & MYCA1 transcription factor & chr15:19338471..19344460 \\
WDR1 & WDR1 transcription factor & chr16:21200996..21204227 \\
MYB4like & MYB4like transcription factor & chr14:17967626..17969826 \\
\hline & & \\
\hline
\end{tabular}

ratios. DNAs were sent to BGI Tech Solutions Co., Ltd., (Hong Kong) for high-throughput sequencing of 21 genes involved in the biosynthetic pathway of anthocyanins (Table 2). After data filtering and mapping against the 12X grapevine reference genome (http://www.genoscope.cns.fr/externe/GenomeBrowser/Vitis/), the company provided, per each gene and sample, a list of SNPs (Single Nucleotide Polymorphisms) and InDels (Insertion/Deletions).

\subsection{Data analysis}

For phenotypic data, descriptive statistics and Principal Component Analysis (PCA) were carried out by using SPSS statistical software (version PASW Statistics 21, SPSS Inc. Chicago, Illinois).

The SNP and InDel lists per each sample were merged to obtain a dataset of polymorphic loci. When the recorded allele was the same as that of reference genome, it was given a " 0 " code, while " 1 " indicated the alternative allele. The final dataset was obtained by removing loci which were monomorphic and with an allelic frequency lower than 0.05 (MAF).

The SNP-InDel dataset was used to investigate the genetic relationships among genotypes by both cluster analysis and Sparse Partial Least Squares regression with Discriminant Analysis (SPLS-DA). For cluster analysis, a distance matrix was set up on Nei's distances [23], calculated by the poppr [24] package implemented in R 3.6 software [25]. The Unweighted Pair Group Method with Arithmetic Mean (UPGMA) algorithm implemented in MEGA 5.0 software [26] was used for clustering and plotting the circular dendrogram. SPLS-DA was performed using the mixOmics [27] package implemented in R 3.6 software. 
Correlation between phenotypic and genetic data was performed in R 3.6 using Pearson's correlation coefficient. Pearson's correlation matrix was viewed via heatmap and hierarchical clustering, performed using the function heatmap. 2 implemented in gplots $\mathrm{R}$ package [28]. Only pairwise of variables showing a Pearson's correlation value $\geq|0.70|$ ( $p$-value $<=0.05$ ) were considered biologically relevant and were discussed.

\section{Results and discussion}

\subsection{Phenotypic description}

A wide range of carpological variability among the cultivars selected was observed (Table 3). For example, the berry weight ranged from the 25th (Cardinal) to 90th (Cabernet Sauvignon) percentiles of V. vinifera variability reported in Rustioni et al. [29], but it was mainly composed of big berries (the average still fell into the 90th percentile). Similar data concerned the skin weight, ranging from the 20th to 90th percentiles, but with an average falling in the 60th percentile. This means that our cultivar set already included genotypes of interest for table grape selection, having big berries and thin skins (despite the higher surface expected in big berries, the average skin weight falls into a lower percentile than the berry weight).

Table 4 summarizes the anthocyanin profiles, while one HPLC chromatogram per each cultivar is shown in Fig. 1. It is well known that malvidin-3-O-glucoside is the major pigment in grapes [30]. Nevertheless, it was observed a bias towards the disubstituted pigments, mainly cyanidin-3-O-glucosides. This is due to the artificially targeted selection during the century of pink grape cultivars affected by disfunctions in the metabolic pathway of anthocyanins and, thus, the distribution here reported should not be considered representative of the $V$. vinifera species in general. In agreement with previous observations [2, 3], no cultivars showed a dominance of delphinidin-3-O-glucoside or petunidin-3-O-glucosides.

When considering the total anthocyanin concentrations (Table 5), most of the studied cultivars showed a low pigment accumulation, with seven genotypes (Coada Vulpii, Comtessa, Faberrebe, Fernand Rose, Ghrubela Kartlis, Grignolino and Rkatsiteli Vardisperi) having values lower than the 10th percentiles reported in Rustioni et al. [29], when expressed in $\mathrm{mg} / \mathrm{kg}$ of grapes. Nevertheless, considering the decreased ratio surface/volume of big berries, the situation appears less extreme when total anthocyanins are measured in $\mathrm{mg} / \mathrm{g}$ of skins or $\mathrm{mg} / \mathrm{g}$ of berry (indeed, the average value shifts from the 25th percentiles to the 40th percentiles of the species variability reported in Rustioni et al. [29]). Most of the genotypes studied in the present work have lightly-pigmented berries: they were selected with the objective of highlighting disfunctions in the pigment accumulation.

PCAs were carried out on quality and quantity of anthocyanins data. In Table 6, the results of PCA are reported. When considering the pigment quantity (total anthocyanins parameters, colour index and colour group) only one PCA function produced an eigenvalue higher than 1 (4.56, explaining $75.93 \%$ of the variance). The matrix of the component is reported in the Supplementary material S1A, and shows that all the considered parameters had a high weight in the function.

The pigment quality is summarized by a PCA calculated on the anthocyanin profiles obtained by HPLC analysis. Three functions having eigenvalues higher than $1(10.77,3.85$ and 1.44$)$ were obtained, explaining a total of $94.41 \%$ of the variance (subdivided in $63.33 \%, 22.64 \%$ and $8.45 \%$; Supplementary material S1B). The first function represents the B ring substitution. The B ring substitution and the esterification of anthocyanins have already been used in several studies on chemotaxonomy. Among them, interesting results coherent with our data, are presented in Mattivi et al. [1] and Mattivi et al. [2].

The second function mostly represents delphinidin-3-O-glucoside and peonidin-3-O-glucoside, as well as some parameters related to the acylation (acetate pigments and the ratio between acetate/ $p$-coumarate pigments). The third function is mainly related to peonidin-3-O-glucoside and the acetylation type. Figure 2 represents the graph of the first two components obtained by the PCA related to the pigment quality. Although these functions clearly discriminate the genotypes based on their prevalent anthocyanin (represented in blue for cyanidin-3-O- 
Table 3

Carpological description of the 15 grape varieties analyzed

\begin{tabular}{|c|c|c|c|c|c|c|c|c|c|c|c|c|c|c|c|c|c|c|c|c|}
\hline \multirow[b]{2}{*}{$\begin{array}{l}\text { Phenotypic } \\
\text { parameter }\end{array}$} & \multicolumn{16}{|c|}{ Singular genotype description } & \multicolumn{4}{|c|}{ Variability among genotypes } \\
\hline & & 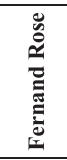 & 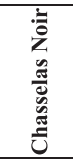 & 莺 & 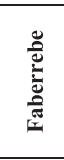 & 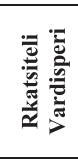 & 爮 & $\begin{array}{l}\text { ज्ञ } \\
\text { 竎 } \\
\text { Uే }\end{array}$ & 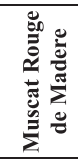 & 造 & 吾 & 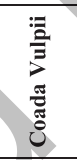 & 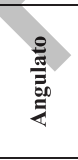 & 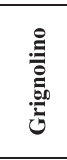 & 总 & 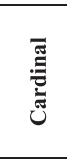 & 恶 & $\sum_{\pi}^{\frac{\pi}{\pi}}$ & 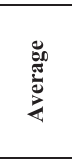 & 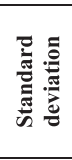 \\
\hline \multirow{2}{*}{$\begin{array}{l}\text { Berry surface } \\
\left(\mathrm{mm}^{2}\right)\end{array}$} & Ave. & 786 & 1340 & 621 & 800 & 945 & 556 & 817 & 922 & 1065 & 802 & 1349 & 1188 & 735 & 784 & 1664 & 556 & 1664 & 958 & 307 \\
\hline & st. dev. & 45 & 144 & 65 & 65 & 70 & 43 & & & 132 & 56 & 375 & 90 & 66 & 17 & 475 & $\begin{array}{l}\text { Cabernet } \\
\text { Sauvignon }\end{array}$ & Cardinal & & \\
\hline \multirow[b]{2}{*}{ Berry weight (g) } & Ave. & 2.54 & 5.77 & 1.71 & 2.86 & 3.38 & 1.61 & 2.48 & 3.42 & 3.9 & 2.62 & 5.68 & 4.72 & 2.2 & 2.63 & 7.42 & 1.61 & 7.42 & 3.53 & 1.68 \\
\hline & st. dev. & 0.12 & 1.02 & 0.27 & 0.39 & 0.36 & 0.19 & 0.17 & 0.54 & 0.71 & 0.32 & 2.3 & 0.4 & 0.25 & 0.25 & 2.83 & $\begin{array}{l}\text { Cabernet } \\
\text { Sauvignon }\end{array}$ & Cardinal & & \\
\hline \multirow[b]{2}{*}{ Skin weight (g) } & Ave. & 0.42 & 0.37 & 0.31 & 0.36 & 034 & 0.21 & 0.3 & 0.3 & 0.56 & 0.27 & 0.62 & 0.27 & 0.32 & 0.36 & 1.09 & 0.21 & 1.09 & 0.41 & 0.22 \\
\hline & st. dev. & 0.02 & 0.03 & 0.05 & 0.05 & & 06 & 0.04 & 0.04 & 0.15 & 0.02 & 0.04 & 0.05 & 0.02 & 0.07 & 0.42 & $\begin{array}{l}\text { Cabernet } \\
\text { Sauvignon }\end{array}$ & Cardinal & & \\
\hline \multirow{2}{*}{ Volume $\left(\mathrm{mm}^{3}\right)$} & Ave. & 2075 & 4620 & 1460 & 2128 & 29 & 1232 & 2191 & 2628 & 3280 & 2134 & 4747 & 3849 & 1871 & 2059 & 6506 & 1232 & 6506 & 2900 & 1452 \\
\hline & st. dev. & 180 & 738 & 224 & & 311 & 144 & 63 & 467 & 604 & 232 & 1856 & 444 & 253 & 63 & 2825 & $\begin{array}{l}\text { Cabernet } \\
\text { Sauvignon }\end{array}$ & Cardinal & & \\
\hline
\end{tabular}


Table 4

HPLC anthocyanin profiles of the 15 grape varieties analyzed

\begin{tabular}{|c|c|c|c|c|c|c|c|c|c|c|c|c|c|c|c|c|c|c|c|c|}
\hline \multirow[b]{2}{*}{$\begin{array}{l}\text { Phenotypic } \\
\text { parameter }\end{array}$} & \multicolumn{16}{|c|}{ Singular genotype description } & \multicolumn{4}{|c|}{ Variability among genotypes } \\
\hline & & 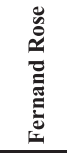 & 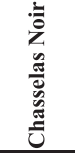 & 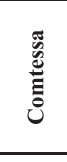 & 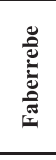 & 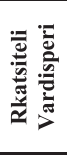 & 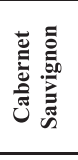 & 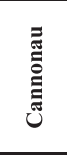 & 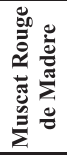 & 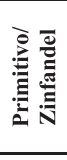 & لَّ & 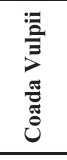 & $\begin{array}{l}\frac{8}{5} \\
\frac{5}{50} \\
\frac{5}{2}\end{array}$ & 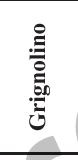 & 总 & Uूँ & $\dot{z}$ & $\sum^{\frac{\pi}{\pi}}$ & 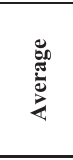 & 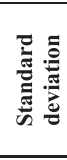 \\
\hline \multirow{2}{*}{$\begin{array}{l}\text { Delphinidin 3-O- } \\
\text { glucoside (\%) }\end{array}$} & Ave. & 0.89 & 18.27 & 3.72 & 2.48 & 3.32 & 17.47 & 4.94 & 9.18 & 8.93 & 10.74 & 1.6 & & 1.07 & 6.87 & 1.22 & 0.89 & 18.27 & 6.29 & 5.64 \\
\hline & st. dev. & 0.59 & 3.39 & 0.56 & 0.85 & 1.79 & 3.19 & 2.59 & 1.6 & 0.45 & 3.04 & & & 0.83 & 1.7 & 0.21 & $\begin{array}{l}\text { Fernand } \\
\text { Rose }\end{array}$ & $\begin{array}{l}\text { Chasselas } \\
\text { Noir }\end{array}$ & & \\
\hline \multirow{2}{*}{$\begin{array}{l}\text { Cyanidin 3-O- } \\
\text { glucoside (\%) }\end{array}$} & Ave. & 97.79 & 69.36 & 94.02 & 96.3 & 93.9 & 5.21 & 1.25 & 1.52 & 2.68 & 44 & 28.73 & 44.39 & 19 & 26.97 & 10.55 & 1.25 & 97.79 & 39.81 & 39.28 \\
\hline & st. dev. & 0.62 & 4.59 & 1.05 & 1.02 & 2.92 & 0.95 & 0.44 & 0.49 & 1.15 & 2.8 & 10.32 & 2.25 & 7.82 & 7.1 & 2.55 & Cannonau & $\begin{array}{l}\text { Fernand } \\
\text { Rose }\end{array}$ & & \\
\hline \multirow{2}{*}{$\begin{array}{l}\text { Petunidin 3-O- } \\
\text { glucoside (\%) }\end{array}$} & Ave. & 0.18 & 3.12 & 0.28 & 0.09 & 0.22 & 10.74 & 6.44 & & 11.67 & 10.24 & 1.78 & 2.21 & 1.22 & 3.99 & 1.48 & 0.09 & 11.67 & 4.16 & 4.25 \\
\hline & st. dev. & 0.07 & 0.71 & 0.31 & 0.11 & 0.14 & 1.38 & & & & 2.15 & 1.28 & 0.84 & 1.09 & 0.73 & 0.57 & Faberrebe & $\begin{array}{l}\text { Primitivo/ } \\
\text { Zinfandel }\end{array}$ & & \\
\hline \multirow{2}{*}{$\begin{array}{l}\text { Peonidin 3-O- } \\
\text { glucoside (\%) }\end{array}$} & Ave. & 1.06 & 7.62 & 1.58 & 0.87 & 2.18 & 14.7 & 9.4 & 8.81 & 9.63 & 15.61 & 59.15 & 44.4 & 60.97 & 35.57 & 62.27 & 0.87 & 62.27 & 22.25 & 23.43 \\
\hline & st. dev. & 1.08 & 2.92 & 0.36 & 0.12 & & 2.38 & 2.22 & 3.64 & 2.96 & 7.61 & 4.39 & 3.13 & 11.09 & 5.68 & 8.05 & Faberrebe & Cardinal & & \\
\hline \multirow{2}{*}{$\begin{array}{l}\text { Malvidin 3-O- } \\
\text { glucoside (\%) }\end{array}$} & Ave. & 0.57 & 1.63 & 0.4 & 6 & & 51.88 & 77.97 & 71.72 & 67.09 & 57.97 & 8.74 & 5.56 & 17.47 & 26.6 & 24.48 & 0.26 & 77.97 & 27.51 & 29.45 \\
\hline & st. dev. & 1.14 & 0.61 & 0.14 & 33 & 0.2 & 4.65 & 4.16 & 2.99 & 4.37 & 5.39 & 5.8 & 2.96 & 15.43 & 10.25 & 9.81 & Faberrebe & Cannonau & & \\
\hline \multirow{2}{*}{$\begin{array}{c}\text { Disubstituted } \\
\text { anthocyanins (\%) }\end{array}$} & Ave. & 98.85 & r & & & 96.08 & 19.91 & 10.65 & 10.34 & 12.31 & 21.05 & 87.87 & 88.8 & 79.97 & 62.54 & 72.82 & 10.34 & 98.85 & 62.06 & 36.02 \\
\hline & st. dev. & & & & 0.98 & 2.1 & 3.14 & 2.65 & 4.11 & 4.09 & 10.37 & 8.06 & 4.89 & 17.32 & 11.2 & 10.51 & $\begin{array}{c}\text { Muscat } \\
\text { Rouge de M. }\end{array}$ & $\begin{array}{l}\text { Fernand } \\
\text { Rose }\end{array}$ & & \\
\hline \multirow{2}{*}{$\begin{array}{c}\text { Trisubstituted } \\
\text { anthocyanins (\%) }\end{array}$} & Ave. & 1.63 & 23.03 & 4.4 & 2.83 & 3.92 & 80.09 & 89.35 & 89.66 & 87.69 & 78.95 & 12.13 & 11.2 & 20.03 & 37.46 & 27.18 & 1.63 & 89.66 & 37.97 & 35.98 \\
\hline & st. dev. & 0.99 & 4.2 & 0.78 & 0.98 & 2.1 & 3.14 & 2.65 & 4.11 & 4.09 & 10.37 & 8.06 & 4.89 & 17.32 & 11.2 & 10.51 & $\begin{array}{l}\text { Fernand } \\
\text { Rose }\end{array}$ & $\begin{array}{c}\text { Muscat } \\
\text { Rouge de M. }\end{array}$ & & \\
\hline
\end{tabular}




\begin{tabular}{|c|c|c|c|c|c|c|c|c|c|c|c|c|c|c|c|c|c|c|c|c|}
\hline $\begin{array}{l}\text { Non-methoxylated } \\
\text { anthocyanins (\%) }\end{array}$ & Ave. & 98.68 & 87.63 & 97.74 & 98.78 & 97.21 & 22.68 & 6.19 & 10.7 & 11.6 & 16.18 & 30.33 & 47.82 & 20.34 & 33.84 & 11.77 & 6.19 & 98.78 & 46.1 & 38.05 \\
\hline & st. dev. & 1 & 3.46 & 0.59 & 0.45 & 1.14 & 3.53 & 2.41 & 1.3 & 1.44 & 1.05 & 9.44 & 1.43 & 7.14 & 7.12 & 2.37 & Cannonau & Faberrebe & & \\
\hline \multirow{2}{*}{$\begin{array}{c}\text { Methoxylated } \\
\text { anthocyanins (\%) }\end{array}$} & Ave. & 1.81 & 12.37 & 2.26 & 1.22 & 2.79 & 77.32 & 93.81 & 89.3 & 88.4 & 83.82 & 69.67 & 52.18 & 79.66 & 66.16 & 88.23 & 1.22 & 93.81 & 53.93 & 38 \\
\hline & st. dev. & 2.08 & 3.46 & 0.59 & 0.45 & 1.14 & 3.53 & 2.41 & 1.3 & 1.44 & 1.05 & 9. & 1.43 & & 7.12 & 2.37 & Faberrebe & Cannonau & & \\
\hline \multirow{2}{*}{$\begin{array}{c}\text { Percentage of } \\
\text { methoxylation (\%) }\end{array}$} & Ave. & 2.28 & 11.37 & 2.54 & 1.44 & 3.03 & 71.75 & 90.74 & 84.92 & 82.82 & 79.32 & 69.47 & 51.89 & 80.17 & 67.11 & 88.46 & 1.44 & 90.74 & 52.49 & 36.69 \\
\hline & st. dev. & 3 & 3.05 & 0.51 & 0.73 & 1.22 & 4.38 & 3.91 & 1.46 & 1.4 & 2.1 & 8.64 & 1.77 & 7.37 & 6.72 & 2.27 & Faberrebe & Cапnопаи & & \\
\hline \multirow{2}{*}{$\begin{array}{l}\text { ortho-Diphenols } \\
(\%)\end{array}$} & Ave. & 98.86 & 90.75 & 98.02 & 98.87 & 97.44 & 33.43 & 12.63 & 19.46 & 23.28 & 26.43 & 32.11 & 50.04 & 21.56 & 37.83 & 13.25 & 12.63 & 98.87 & 50.26 & 35.35 \\
\hline & st. dev. & 1.04 & 3.1 & 0.3 & 0.43 & 1.01 & 4.85 & 4.99 & 1.65 & 1.64 & 2.7 & 8.29 & 1.38 & 6.26 & 7.01 & 1.85 & Cannonau & Faberrebe & & \\
\hline \multirow{2}{*}{$\begin{array}{c}\text { Non ortho- } \\
\text { Diphenols (\%) }\end{array}$} & Ave. & 1.63 & 9.25 & 1.98 & 1.13 & 2.56 & 66.57 & 87.37 & 80.54 & 76.72 & 73.57 & 67.89 & 49.96 & 78.44 & 62.17 & 86.75 & 1.13 & 87.37 & 49.77 & 35.3 \\
\hline & st. dev. & 2.12 & 3.1 & 0.3 & 0.43 & 1.01 & 4.85 & 4.99 & 1.65 & 1.64 & 2.7 & 8.29 & 1.38 & 6.26 & 7.01 & 1.85 & Faberrebe & Cannonau & & \\
\hline \multirow{2}{*}{$\begin{array}{c}\text { Monoglucosides } \\
(\%)\end{array}$} & Ave. & 98.5 & 80.63 & 99.57 & 99.35 & 99.05 & 56.39 & 83.96 & 74.13 & 77.14 & 53.8 & 89.66 & 91.74 & 96.78 & 85.07 & 91.02 & 53.8 & 99.57 & 85.12 & 14.72 \\
\hline & st. dev. & 0.22 & 1.59 & 0.18 & 0.1 & 0.23 & 3.61 & 1.53 & 2.65 & 2.54 & 10.06 & 1.92 & 2.54 & 0.49 & 1.91 & 1.08 & $\begin{array}{l}\text { Ghrubela } \\
\text { Kartlis }\end{array}$ & Comtessa & & \\
\hline \multirow{2}{*}{$\begin{array}{l}\text { Acylated pigments } \\
(\%)\end{array}$} & Ave. & 1.5 & 19.37 & 0.43 & 0.65 & 0.95 & 43.61 & 16.04 & 25.87 & 22.86 & 46.2 & 10.34 & 8.26 & 3.22 & 14.93 & 8.98 & 0.43 & 46.2 & 14.88 & 14.72 \\
\hline & st. dev. & 0.22 & 1.59 & 0.18 & 0. & 0.23 & & 1.53 & 2.65 & 2.54 & 10.06 & 1.92 & 2.54 & 0.49 & 1.91 & 1.08 & Comtessa & $\begin{array}{l}\text { Ghrubela } \\
\text { Kartlis }\end{array}$ & & \\
\hline \multirow{2}{*}{$\begin{array}{l}\text { Acetated pigments } \\
(\%)\end{array}$} & Ave. & 0.78 & 10.95 & 0.22 & 0.35 & 0.24 & 35.02 & 3.33 & 4.26 & 4.01 & 6.99 & 1.24 & 1.76 & 0.68 & 5.14 & 0.43 & 0.22 & 35.02 & 5.03 & 8.84 \\
\hline & st. dev. & 0.13 & 1.3 & 0.1 & & 0.06 & 2.52 & 0.47 & 0.65 & 0.41 & 0.98 & 0.09 & 0.26 & 0.09 & 1.1 & 0.25 & Comtessa & $\begin{array}{l}\text { Cabernet } \\
\text { Sauvignon }\end{array}$ & & \\
\hline \multirow{2}{*}{$\begin{array}{l}p \text {-coumarate } \\
\text { pigments (\%) }\end{array}$} & Ave. & 0.72 & 8.42 & 1 & 0.3 & 0.71 & 8.59 & 12.71 & 21.61 & 18.85 & 39.21 & 9.1 & 6.5 & 2.53 & 9.79 & 8.55 & 0.21 & 39.21 & 9.85 & 10.39 \\
\hline & st. dev. & 0.09 & 1.29 & 0.08 & 0.11 & 0.17 & 1.35 & 1.13 & 3.25 & 2.19 & 9.64 & 1.91 & 2.42 & 0.46 & 2.28 & 1.04 & Comtessa & $\begin{array}{l}\text { Ghrubela } \\
\text { Kartlis }\end{array}$ & & \\
\hline \multirow{2}{*}{$\begin{array}{l}\text { Ratio acetate/p- } \\
\text { coumarate } \\
\text { pigments }\end{array}$} & Ave. & 1.08 & 1.33 & 1.06 & 1.34 & 0.33 & 4.14 & 0.26 & 0.2 & 0.21 & 0.19 & 0.14 & 0.3 & 0.28 & 0.56 & 0.05 & 0.05 & 4.14 & 0.77 & 1.03 \\
\hline & st. dev. & 0.1 & 0.3 & 0.25 & 0.54 & 0.05 & 0.52 & 0.02 & 0.06 & 0.01 & 0.05 & 0.03 & 0.11 & 0.05 & 0.22 & 0.03 & Cardinal & $\begin{array}{l}\text { Cabernet } \\
\text { Sauvignon }\end{array}$ & & \\
\hline
\end{tabular}


Table 5 Reflectance spectroscopy characterization of the 15 grape varieties analyzed

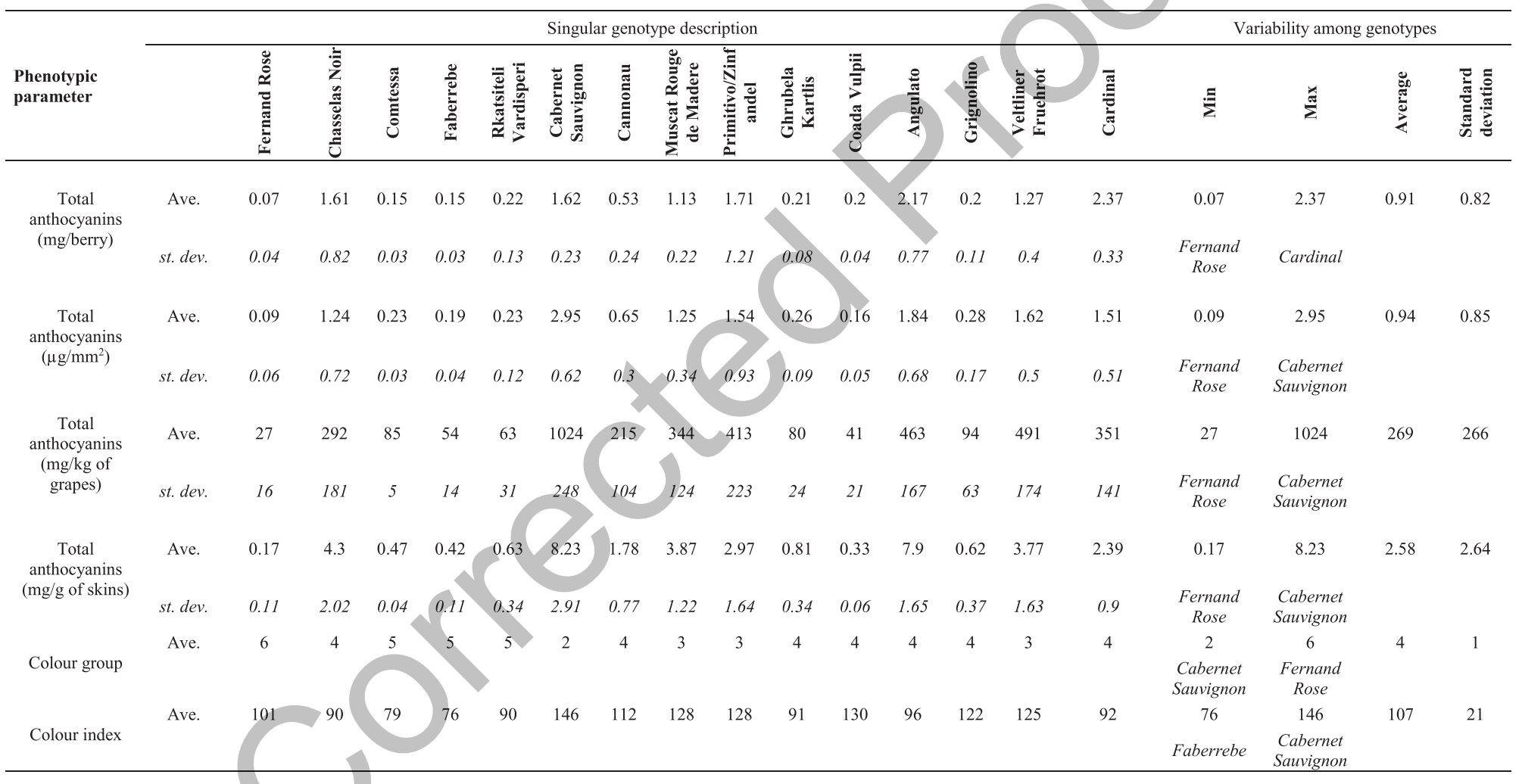


Table 6

PCA components of pigment quality (HPLC data) and quantity (spectrophotometric data) parameters of the 15 grape varieties analyzed

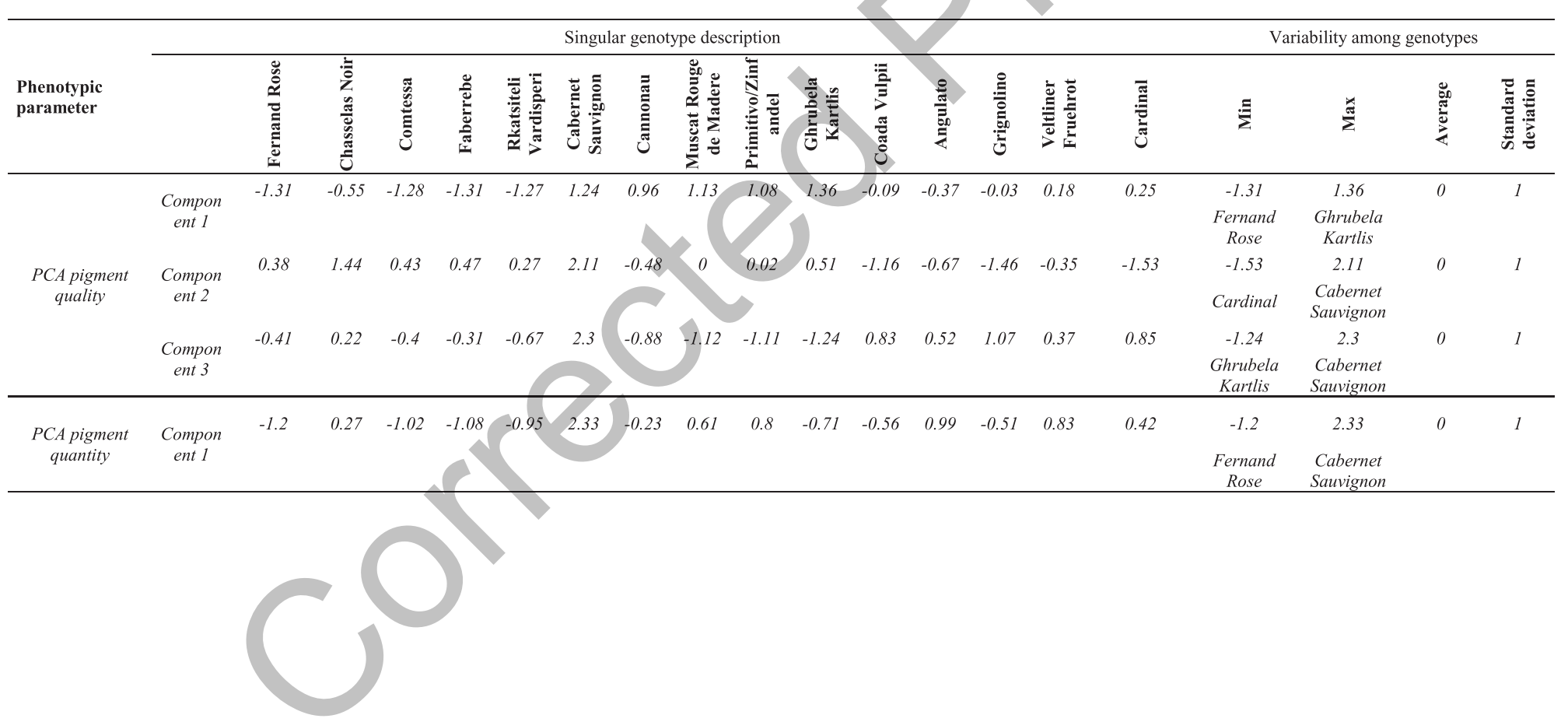



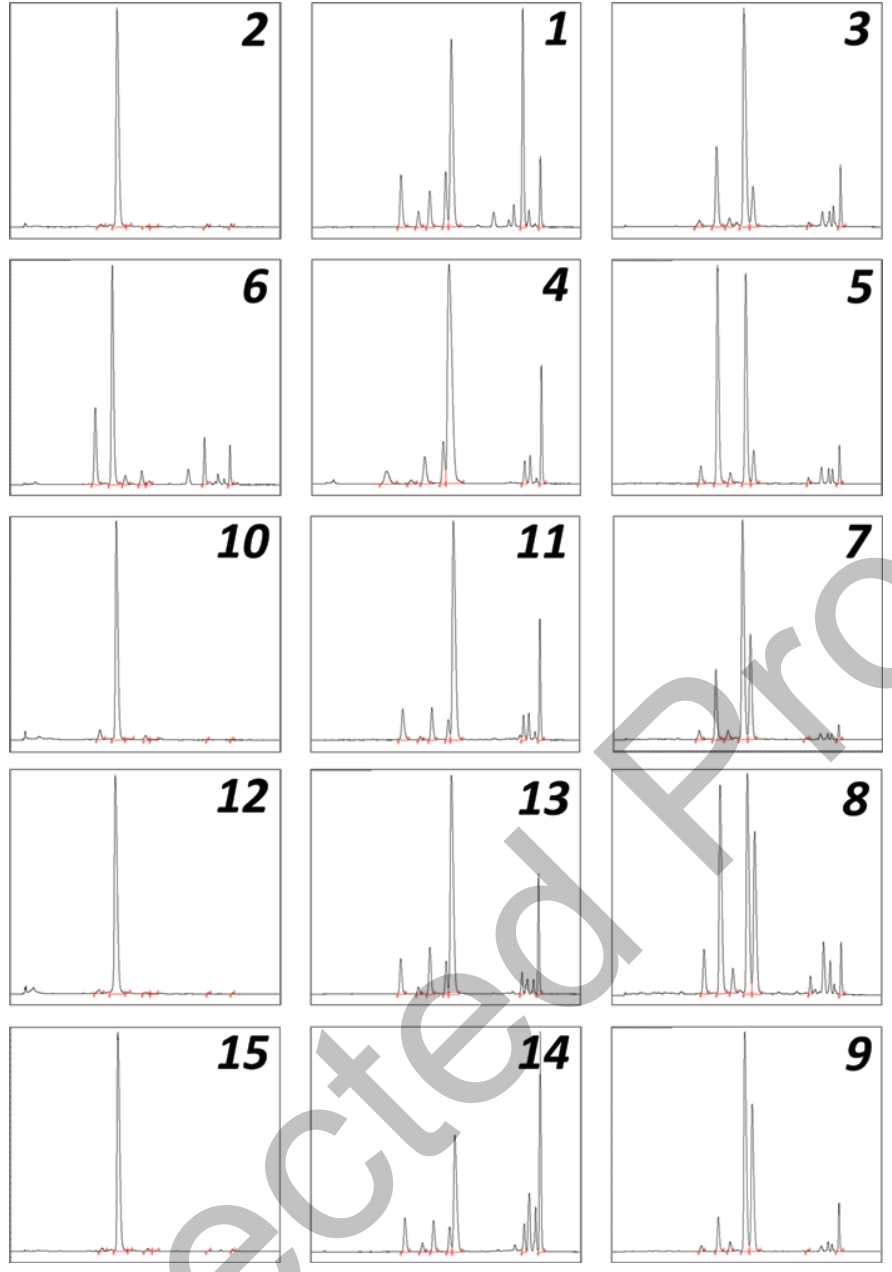

Fig. 1. HPLC anthocyanin profiles of 15 grape varieties. The varieties are arranged based on their predominant anthocyanin (columns). The varieties are identified by the ID sample reported in Table 1 .

glucoside, in red for peonidin-3-O-glucoside and in green for malvidin-3-O-glucoside), variability within the groups has been detected as well. The conclusion is, thus, that the cultivars were selected to represent enough phenotypic variability.

\subsection{Genotypic description}

Twenty-one genes related to the anthocyanin biosynthesis in grape berries were in-depth sequenced via the targeted resequencing technology. The sequencing produced a mean of $1.07 \times 10^{6}$ reads per sample, with an average read length of $98 \mathrm{bp}$ and $92 \%$ of target regions showing a 20x coverage. Ninety-two percent of the reads were mapped on the reference genome and $65 \%$ of them were successfully mapped on target regions. The percentage of mapped reads was similar to those obtained in other works (such as Carrier et al. [31]).

Once the mapping against the grapevine reference genome was performed, the alternative alleles, with respect to the reference genome, were recorded (Supplementary material S2 and S3). Table 7 reports an overview 


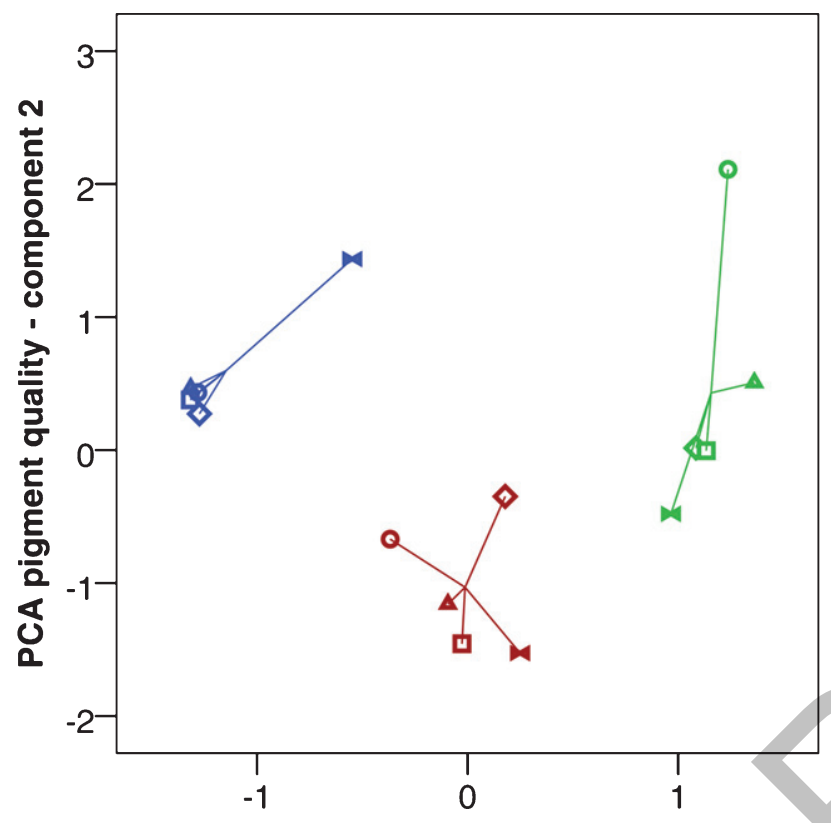

\section{Cultivar}

Angulato

- Cabernet Sauvignon

Cannonau

M Cardinal

Chasselas noir

$\triangle$ Coada Vulpii

- Comtessa

$\Delta$ Faberrebe

$\square$ Fernand Rose

$\triangle$ Ghrubela Kartlis

- Grignolino

Muscat Rouge de

Madere

$\checkmark$ Primitivo/Zinfandel

$\checkmark$ Rkatsiteli Vardisperi

$\checkmark$ Veltliner Fruehrot

\section{PCA pigment quality - component 1}

Fig. 2. Plot of the first two components obtained by PCA results related to the pigment quality parameters for 15 grape varieties. Different colors indicate different prevalent anthocyanin (blue $=$ cyanidin-3- $O$-glucoside, red = peonidin-3-O-glucoside, green $=$ malvidin-3-O-glucoside) .

of identified polymorphisms. A total of 1751 polymorphic loci were scored. The high number of detected polymorphic loci corroborates that the next generation sequencing technology as the most powerful way to search for genetic polymorphisms [32, 33]. Sixty-height percent of polymorphic loci were SNPs (1183 out of 1751) and $32 \%$ were InDels (568). InDel polymorphisms ranged from 2 to 33 bps. InDels are less abundant than SNPs $[34,35]$. The frequency of InDels is higher when compared to SNPs, due to the low resolution of polymerases at short repeats [36]. The F3' 5' $\mathrm{H}$ gene showed the lowest number of polymorphisms (6), while AOMT2 gene recorded the highest number of polymorphisms (222) (Table 7). The loci were filtered for monomorphic ones (51 loci were identified, 41 loci accounted for SNPs and 10 for InDels) and for MAF $<0.05$ (513 loci were removed, 356 loci accounted for SNPs and 156 for InDels), resulting in a final dataset of 1188 polymorphic loci (880 SNPs and 308 InDels) (Supplementary material S4).

Cluster analysis and SPLS-DA were used to investigate the genetic relationships among the cultivars (Fig. 3). The genetic profiles showed similarity values ranging from 72 to $86 \%$ (Fig. 3A), confirming the wide range of phenotypical variability described (Table 3, 4,5 and 6). The genotyping of 21 genes involved in the biosynthesis of anthocyanins allowed the clustering of the genotypes based on their berry anthocyanin profiles, with few exceptions. Cultivars were separated into two main groups, based on the percentage of disubstituted (Group 1) or trisubstituted (Group 2) anthocyanins. In Group 1, two minor sub-groups were detected, which discriminate between genotypes accumulating mainly cyanidin-3-O-glucoside (except for Fernand Rose, \#2) and peonidin-3$O$-glucoside (except for Grignolino, \#7). These two sub-groups included cultivars belonging to Colour groups 4 and 5 (except for Veltliner Fruherot, \#8) (Table 5). Group 2 appeared the more heterogeneous, with a sub-cluster of cultivars accumulating mainly malvidin-3-O-glucoside and another one which included two cultivars with a contrasting anthocyanin profile (Cabernet Sauvignon, \#1, and Fernand Rose, \#2). It is tempting to speculate that the discrepancies observed when clustering genotypes based on genotyping or anthocyanin content may be due to polymorphisms accumulated in non-coding sequences. 
Table 7

Overview of polymorphisms identified after sequencing of 21 genes related to the anthocyanin biosynthetic pathway in 15 grape varieties. SNPs: Single Nucleotide Polymorphisms; InDel: Insertion/Deletions

\begin{tabular}{lccc}
\hline Genes & Number of polymorphic loci & Number of SNPs & Number of Indels \\
\hline F3'H & 206 & 136 & 70 \\
F3'5'H & 6 & 5 & 1 \\
F3H1 & 58 & 38 & 20 \\
F3H2 & 97 & 80 & 17 \\
DFR & 99 & 74 & 25 \\
LDOX & 24 & 18 & 6 \\
UFGT & 105 & 91 & 14 \\
AOMT1 & 191 & 57 & 134 \\
AOMT2 & 222 & 140 & 82 \\
AOMT3 & 127 & 80 & 47 \\
MYBPA1 & 43 & 33 & 10 \\
Myb5a & 34 & 25 & 9 \\
Myb5b & 58 & 37 & 21 \\
MybA1 & 22 & 18 & 4 \\
MybA2 & 29 & 22 & 7 \\
Myb4a & 63 & 33 & 30 \\
Myb4b & 35 & 29 & 6 \\
MYBC2-L2 & 33 & 25 & 8 \\
MYCA1 & 116 & 100 & 16 \\
WDR1 & 104 & 88 & 16 \\
MYB4like & 79 & 54 & 25 \\
Total & 1751 & 1183 &
\end{tabular}

A

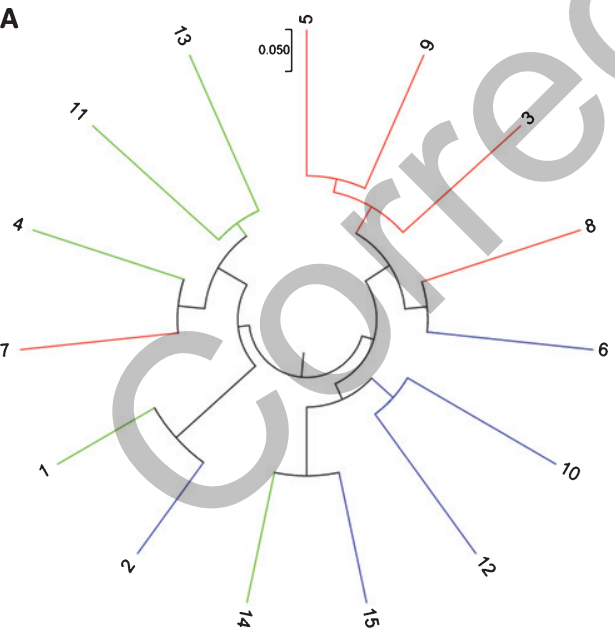

B

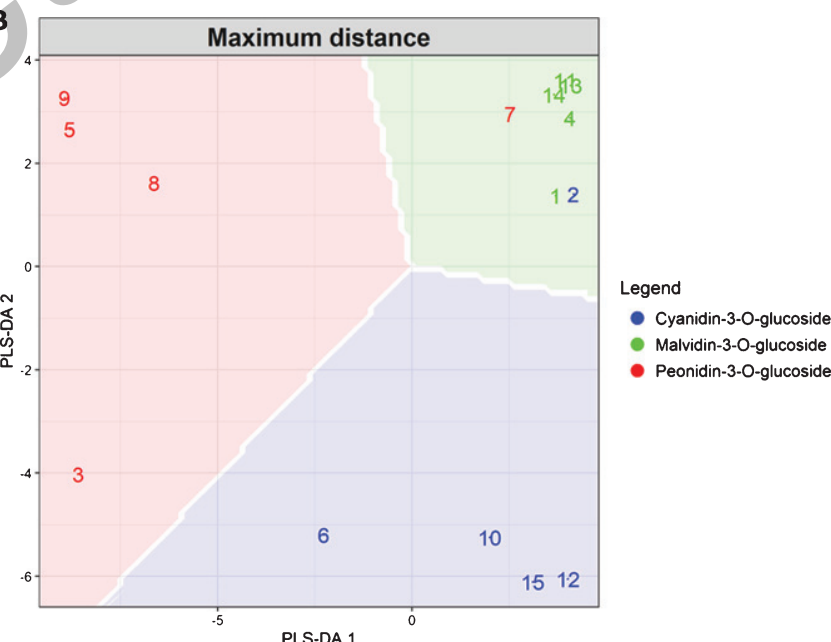

Fig. 3. Genetic relationships among 15 grape varieties based on polymorphisms related to 21 genes of anthocyanin biosynthetic pathway. Genotypes are coded as reported in Table 1. Genotypes are arranged based on the prevalent anthocyanin detected in their berry anthocyanin profile. A: UPGMA (Unweighted Pair Group Method with Arithmetic Mean) dendrogram. B: SPLS-DA (Sparse Partial Least Squares regression with Discriminant Analysis) plot; PLS-DA = PLS-DA component. 
SPLS-DA results reflected the anthocyanin profile of genotypes better than cluster analysis (Fig. 3B). The first two PLS-DA components, explaining 12 and $10 \%$ of total variability respectively, discriminated among the phenotypic groups, with the exception of Cabernet Sauvignon (\#1), Fernand Rose (\#2) and Grignolino (\#7). Genotypes accumulating mainly peonidin-3-O-glucoside were separated along the first component, while the cyanidin- and malvidin-3-O-glucoside mainly-synthesizing genotypes were separated along the second component. The variables that mostly contributed to the definition of PLS-DA 1 were loci on chromosome 1 (33 loci), related to the AOMTs, and chromosome 16 (13 loci), related to the UFGT. The PLS-DA 2 originated from loci related to AOMTs and Myb5b (8 loci located on chromosome 6). Anthocyanin $O$-methyltrasferases (AOMT1, 2 and 3) are key enzymes acting downstream of UFGT in catalysing the methylation of cyanidinto peonidin-3-O-glucoside and delphinidin- to both petunidin- and malvidin-3-O-glucoside [9]. In grapevine, AOMT1 is responsible for anthocyanin methylation, while AOMT2 is responsible for specific differences in the levels of methylated anthocyanins [13]. AOMT3 activity was not detected in grape berries. AOMT1 preferentially catalyses the 5' $O$-methylation, synthesizing high amounts of malvindin-3-O-glucoside, and AOMT2 the 3' $O$-methylation [13]. Among the 33 AOMT loci associated with the PLS-DA 1, 19 are related to AOMT2 and present in four out of five of the genotypes mainly synthesizing peonidin-3-O-glucoside (Angulato, Cardinal, Coada Vulpi and Veltiner Fruherot), which showed the same polymorphisms. Ten out of 19 loci were SNPs. The polymorphism at position 20828168 on chromosome 1 is an InDel of 20 bp located 159 bp upstream of the AOMT2 start codon. The insertion was not detected in cultivars accumulating mainly peonidin-3-Oglucoside. It can be speculated that this insertion can modulate AOMT2 expression, reducing the synthesis of peonidin-3-O-glucoside.

Pearson's correlation was used to correlate phenotypic and genetic data (Supplementary material S5). The correlation values were plotted as heatmap (Fig. 4), and only the pairs of variables with Pearson's correlation $\geq|0.70|$ ( $p$-value $<=0.05$ ) were further considered. One hundred and eighteen, out of 28512 combinations, were considered biologically relevant. Supplementary material S6 reports the 118 most significant combinations and the genetic profiles per each analyzed cultivar. The phenotypic parameters showing the highest number of statistically significant correlations were "Ratio acetate/ $p$-coumarate pigments" (47 correlations with polymorphisms related to F3H1, F3'H, UFGT, AOMTs and MYCA1 genes), " $p$-coumarate pigments" (14 correlations with F3'H, UFGT, AOMTs genes) and "Peonidin-3-O-glucoside" (11 correlations with F3'H, UFGT, AOMTs and MYB4-like genes). Other statistically significant correlations were detected for the following phenotypic parameters: "Colour index", "Cyanidin-3-O-glucoside", "Delphinidin-3-O-glucoside", "Methoxylated anthocyanins", "Non-methoxylated anthocyanins", "Percentage of methoxylation" and "Petunidin-3-O-glucoside". The polymorphisms involved in the statistically significant correlations were both SNPs (77\%) and InDels $(23 \%)$.

Two polymorphisms detected in the $\mathrm{F} 3 \mathrm{H} 2$ gene were correlated to the "Colour index" parameter. The alternative alleles $(\mathrm{C} \rightarrow \mathrm{G}$ for chr18_12302686 locus and $\mathrm{CG} \rightarrow \mathrm{C}$ for chr18_12304924) were detected for the cultivars showing the highest value of "Colour index" (the higher the value, the higher the total anthocyanin content). This gene is located upstream of the fork leading to the cyanidin- and delphinidin-based anthocyanins, and it is involved in the synthesis of dihydrokaempferol, together with isoform F3H1. The transcripts of the F3H2 isoform are predominant in the colouring of berry skins [37]. The two alternative alleles detected in the varieties showing the highest "Colour index" can be related to the high value of anthocyanin content. Another locus correlated with the total content of anthocyanins was chr14_17969970, located in the MYB4like gene. The alternative allele $(\mathrm{G} \rightarrow \mathrm{T})$ was detected in the three cultivars showing the highest content of total anthocyanins. This transcription factor was shown to play an important role in the regulation of the grapevine anthocyanin pathway, working as a negative regulator of some structural genes, such as DFR and UFGT [38].

Looking at the quality of the anthocyanin profile, three polymorphisms appeared to be correlated with the percentages of methoxylated, non-methoxylated anthocyanins, and of cyanidin-3-O-glucoside. These loci are chr1_20829800, chr14_17967620 and chr17_8014875, located in the AOMT2, MYB4-like and F3'H genes, 

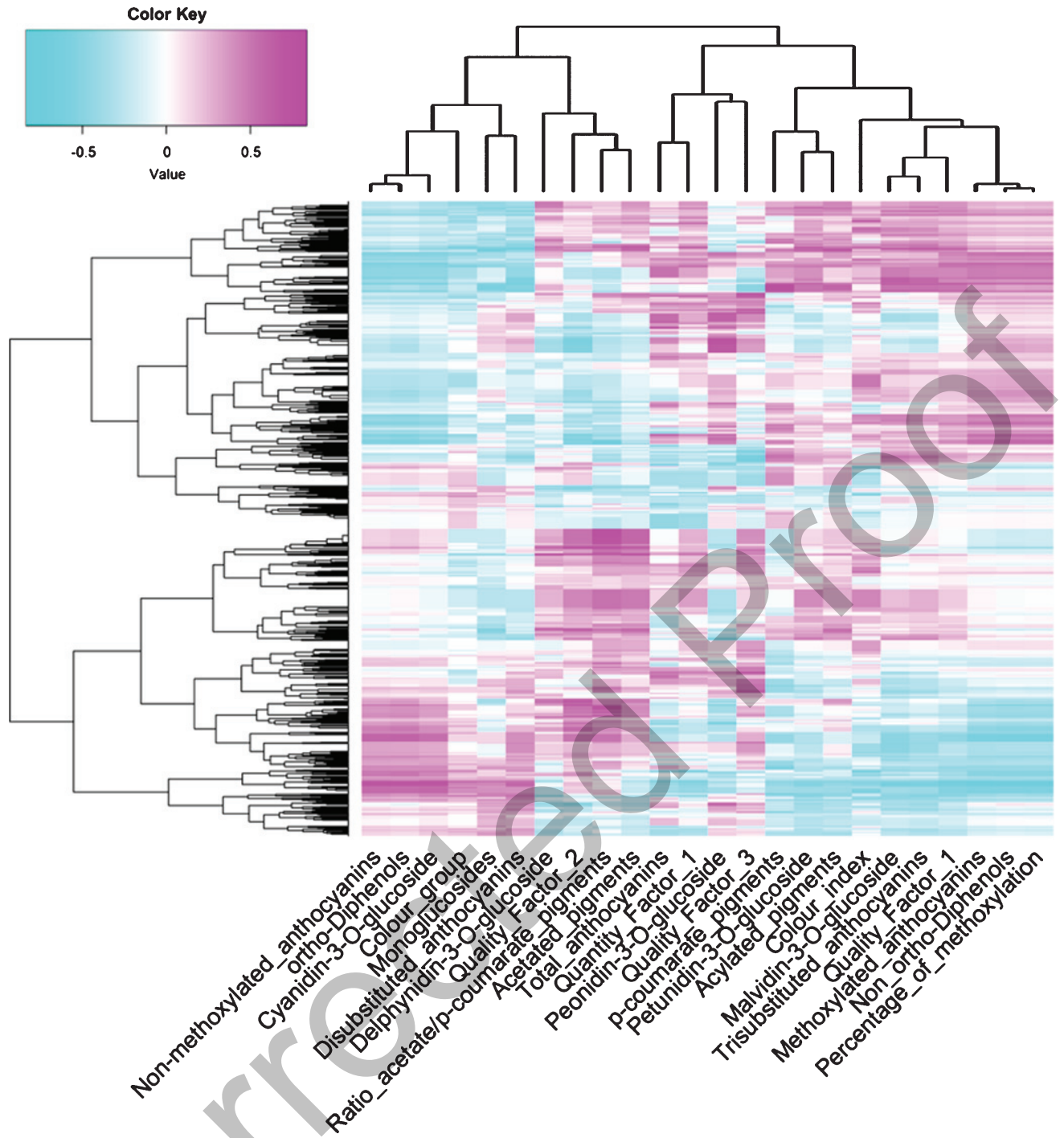

Fig. 4. Heatmap representing correlation matrix (Pearson's coefficient) between phenotypic and genetic data of 15 grape varieties. Pearson's coefficient matrix is reported in Supplementary material S5.

respectively. F3' $\mathrm{H}$ is a gene involved in the biosynthesis of cyanidin-based disubstituted anthocyanins and AOMT2 is the isoform of anthocyanin $O$-methyltransferase that preferentially catalyses the 3 ' $O$-methylation [13]. The correlation between MYB-4 like and the 3' branch of the biosynthetic pathway of anthocyanins may suggest that this transcription factor could be involved in the $3^{\prime} / 3^{\prime} 5^{\prime}$ branch control. Other polymorphisms located in the F3'H gene are correlated with cultivars accumulating high percentages of malvidin-, peonidin- and petunidin-3-O-glucoside (chr17_8011032, chr17_8015131, chr17_8014646, respectively). The cultivars showing high concentrations of petunidin- and delphinidin-3-O-glucoside were correlated with AOMT1, while the ones accumulating a high concentration of peonidin-3-O-glucoside were correlated with AOMT2. 


\section{Conclusions}

This work identifies genetic polymorphisms related to the anthocyanin pathway. The phenotypic parameters showing the highest number of statistically significant correlations with the genetic polymorphisms were related to acylation and the accumulation of peonidin-3-O-glucoside. Further correlations were found for colour intensity and other pigment profile descriptors. Both the quantity and the quality of anthocyanins modify the hue and intensity of the skin colour.

Fruit appearance could strongly affect consumer preferences. Knowledge of the genetic basis of grape colour variability could support the selection of new cultivars, especially for table grape production, with peculiar pinkcoloured berries. A better understanding of pigment biosynthesis in grapes could support the development of cultivar specific vineyard management and winemaking practices for wine production, as well. Further studies will be necessary to strengthen the understanding of this topic.

\section{Acknowledgments}

The authors would like to thank Dr. Lesly Currah for supporting us on English Language Editing. The authors would like to thank Asus for providing hardware.

\section{Funding}

The research was supported by University of Milan, DiSAA, Research Support Plan 2015-2017, Linea 2 A.

\section{Conflict of interest}

The authors have no conflict of interest to report.

\section{Supplementary material}

The supplementary material is available in the electronic version of this article: https://dx.doi.org/10.3233/JBR190478

\section{References}

[1] Mattivi F, Scienza A, Failla O, Villa P, Anzani R, Tedesco G, Gianazza E, Righetti P. Vitis Vinifera: A chemotaxonomic approach. Anthocyanins in the skin. Proceedings of the 5th International Symposium on Grape Breeding. Vitis. 1990;SI:119-33.

[2] Mattivi F, Guzzon R, Vrhovsek U, Stefanini M, Velasco R. Metabolite profiling of grape: flavonols and anthocyanins. J Agric Food Chem. 2006;54:7692-702.

[3] Rustioni L, De Lorenzis G, Hârţa M, Failla O. Pink berry grape (Vitis vinifera L.) characterization: Reflectance spectroscopy, HPLC and molecular markers. Plant Physiol and Bioch. 2016;98:138-45.

[4] Boss PK, Davies C, Robinson SP. Analysis of the Expression of Anthocyanin Pathway Genes in Developing Vitis vinifera L. cv Shiraz Grape Berries and the Implications for Pathway Regulation. Plant Physiol. 1996;111:1059-66.

[5] Matus JT, Loyola R, Vega A, Pena-Neira A, Bordeu E, Arce-Johnson P, Alcalde JA. Post-veraison sunlight exposure induces MYBmediated transcriptional regulation of anthocyanin and flavonol synthesis in berry skins of Vitis vinifera. J Exp Bot. 2009;60(3):853-67. 
[6] Sparvoli F, Martin C, Scienza A, Gavazzi G, Tonelli C. Cloning and molecular analysis of structural genes involved in flavonoid and stilbene biosynthesis in grape (Vitis vinifera L.). Plant Mol Biol. 1994;24:743-55.

[7] Hugueney P, Provenzano S, Verriès C, Ferrandino A, Meudec E, Batelli G, Merdinoglu D, Cheynier V, Schubert A, Ageorges A. A novel cation-dependent $O$-methyltransferase involved in anthocyanin methylation in grapevine. Plant Physiol. 2009;150(4): 2057-70.

[8] Koes R, Vereij W, Quattrocchio F. Flavonoids: a colorful model for the regulation and evolution of biochemical pathways. Trends Plant Sci. 2005;10(5):236-42.

[9] He F, Pan QH, Shi Y, Duan CQ. Biosynthesis and Genetic Regulation of Proanthocyanidins in Plants. Molecules. 2008;13:2674-703.

[10] Ageorges A, Fernandez L, Vialet S, Merdinoglu D, Terrier N. et al. Four specific isogenes of the anthocyanin metabolic pathway are systematically co-expressed with the red colour of grape berries. Plant Sci. 2006;170:372-83.

[11] Walker AR, Lee E, Bogs J, McDavid DAJ, Thomas MK, Robinson SP. White grapes arose through the mutation of two similar and adjacent regulatory genes. Plant J. 2007;49:772-85.

[12] Fournier-Level A, Le Cunff L, Gomez C, Doligez A, Ageorges A et al. Quantitative genetic bases of anthocyanin variation in grape (Vitis vinifera L. ssp sativa) berry: a QTL to QTN integrated study. Genetics. 2009;183:1127-139.

[13] Kobayashi S, Goto-Yamamoto N, Hirochika H. Retrotransposon-induced mutations in grape skin color. Science. 2004;304:982.

[14] Walker AR, Lee E, Robinson SP. Two new grape cultivars, bud sports of Cabernet Sauvignon bearing pale-coloured berries, are the result of deletion of two regulatory genes of the berry colour locus. Plant Mol Biol. 2006;62:623-35.

[15] Vezzulli S, Leonardelli L, Malossini U, Stefanini M, Velasco R, Moser C. Pinot blanc and Pinot gris arose as independent somatic mutations of Pinot noir. J Exp Bot. 2012;63:6359-69.

[16] Migliaro D, Crespan M, Muñoz-Organero G, Velasco R, Moser C, Vezzulli S. Structural dynamics at the berry colour locus in Vitis vinifera L. somatic variants. Aust J Grape Wine Res. 2014;20:485-95.

[17] De Lorenzis G, Squadrito M, Brancadoro L, Scienza A. Zibibbo nero characterization, a red-wine grape revertant of Muscat of Alexandria. Mol Biotechnol. 2015;57(3):265-74.

[18] Ferreira V, Castro I, Carrasco D, Pinto-Carnide O, Arroyo-García R. Molecular characterization of berry skin color reversion on grape somatic variants. J Berry Res 2018;8(3):147-62.

[19] Rustioni L, Basilico R, Fiori S, Leoni A, Maghradze D, Failla O. Grape colour phenotyping: development of a method based on the reflectance spectrum. Phytochem Anal. 2013;24:453-9.

[20] Strahler AH, Strahler A. Introducing physical geography. 3rd ed. New York: J. Wiley \& Sons, Inc.;2003.

[21] Soil Survey Staff. Soil Taxonomy: A Basic System of Soil Classification for Making and Interpreting Soil Surveys. 2nd ed. Washington: US Government Printing Office; 1999.

[22] Meier U. Growth Stages of Mono- and Dicotyledonous Plants. BBCH Monograph. 2nd ed. Berlin: Wissenschafts-Verlag; 2001.

[23] Nei M. Genetic distance between populations. Am Nat. 1972;106:283-92.

[24] Kamvar ZN, Brooks JC, Grünwald NJ. Novel R tools for analysis of genome-wide population genetic data with emphasis on clonality. Front Genet. 2015;6:208.

[25] R Core Team R: A language and environment for statistical computing. R Foundation for Statistical Computing, Vienna, Austria. URL http://www.R-project.org/. 2014.

[26] Tamura K, Peterson D, Peterson N, Stecher G, Nei M, Kumar S. MEGA5: molecular evolutionary genetics analysis using maximum likelihood, evolutionary distance, and maximum parsimony methods. Mol Biol Evol. 2011;28:2731-9.

[27] Rohart F, Gautier B, Singh A, Lê Cao KA. mixOmics: An R package for 'omics feature selection and multiple data integration. PLoS Comput Biol. 2017;13(11):e1005752.

[28] Warnes GR, Bolker B, Lumley T. gplots: Various R programming tools for plotting data, http://cran.r-project.org/web/ packages/gplots/index.html. 2009 .

[29] Rustioni L, Cola G, Maghradze D, Abashidze E, Argiriou A, Aroutiounian R, et al. Description of the Vitis vinifera L. phenotypic variability in eno-carpological traits by a Euro-Asiatic collaborative network among ampelographic collections. Vitis. 2019;58: 37-46.

[30] Boulton R. The copigmentation of anthocyanins and its role in the color of red wine: A critical review. Am J Enol Vitic. 2001;52:67-87.

[31] Carrier G, Le Cunff L, Dereeper A, Legrand D, Sabot F, Bouchez O, Audeguin L, Boursiquot JM, This P. Transposable elements are a major cause of somatic polymorphism in Vitis vinifera L. PLoS One. 2012;7(3):e32973.

[32] Elshire RJ, Glaubitz JC, Sun Q, Poland JA, Kawamoto K, Buckler ES, Mitchell SE. A robust, simple genotyping-by-sequencing (GBS) approach for high diversity species. PLoS ONE. 2011;6:1-10.

[33] Davey JW, Blaxter ML. RADSeq: next-generation population genetics. Brief Funct Genomics. 2010;9:416-23.

[34] Dong QH, Cao X, Guang Y, Yu HP, Korir NK, Wang C, Fang JG. Discovery and characterization of SNPs in Vitis vinifera and genetic assessment of some grapevine cultivars. Sci Hortic-Amsterdam. 2010;125:233-8. 
[35] Di Genova A, Almeida AM, Mun C, Vizoso P, Travisany D, Moraga C, Pinto M, Hinrichsen P, Orellana A, Maass A. Whole genome comparison between table and wine grapes reveals a comprehensive catalog of structural variants. BMC Plant Biol. 2014;14:7.

[36] Carbonell-Bejerano P, Royo C, Mauri N, Ibáñez J, Martínez Zapater JM. Somatic variation and cultivar innovation in grapevine. In: Morata A, Loira I, editors. Advances in Grape and Wine Biotechnology. London: IntechOpen; 2019. doi: 10.5772/intechopen.86443

[37] Jeong ST, Goto-Yamamoto N, Kobayashi S, Esaka M. Effects of plant hormones and shading on the accumulation of anthocyanins and the expression of anthocyanin biosynthetic genes in grape berry skin. Plant Sci. 2004;167:247-52.

[38] Pérez-Díaz JR, Pérez-Díaz J, Madrid-Espinoza J, González-Villanueva E, Moreno Y, Ruiz-Lara S. New member of the R2R3-MYB transcription factors family in grapevine suppresses the anthocyanin accumulation in the flowers of transgenic tobacco. Plant Mol Biol. 2016;90(1-2):63-76. 